\title{
On the law of magnetoelectric machines
}

\section{J. Joubert}

To cite this article: J. Joubert (1880) On the law of magnetoelectric machines, Philosophical Magazine Series 5, 10:62, 298-300, DOI: 10.1080/14786448008626933

To link to this article: http://dx.doi.org/10.1080/14786448008626933

$$
\text { 曲 Published online: } 08 \text { May } 2009 .
$$

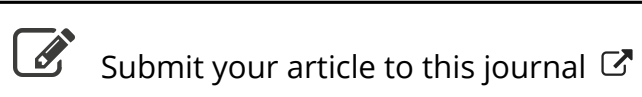

\footnotetext{
Џll Article views: 3
}

Q View related articles $\longleftarrow$ 
specific gravity amounts to 1-2. The fragments of the mineral are stuck upon the ball and the whole put into a solution of iodide of mercury in potassium iodide. The latter is then diluted till the wax ball just floats in it. If $\mathrm{P}, \mathrm{V}, \mathrm{D}$ and $p, v, d$ are respectively the weight, volume, and density of the float and of the substance to be investigated, and $\Delta$ the specific gravity of the liquid, then

$$
d=\frac{p \Delta}{\mathrm{P}+p \Delta \bar{V}}
$$

Wiedemann's Beiblätter, 1880, No. 7, p. 497.

ON THE LAW OF MAGNETOELECTRIC MACHINES. BY J. JOUBERT.

I recently had the honour of communicating to the Academy* the experimental methods which I employ in order to study the laws of the alternating currents used for the production of the electric light. The application of those methods to Siemens's alternate-current machine has shown me that the mean intensity of the current given by that machine is very accurately represented by the formula $I=\frac{C}{\left(R^{2}+m^{2}\right)^{\frac{1}{2}}}$, in which $R$ is the total resistance of the circuit, $m$ a constant depending only on the velocity and varying in the inverse ratio of the duration $T$ of the period; and $\mathrm{C}$ is another constant, equal to the quotient by $\sqrt{ } 2$ of the maximum value of the electromotive force of the machine working with open circuit, measured directly.

The simplicity of the result, and the complete concordance of the experiments with the formulæ, made me think I had before me not merely an empiric formula, but the expression itself of the law of the phenomenon; and I was led to try whether the theory could not conduct me back to that formula.

Let us suppose that the motion of the machine is uniform. Let $\mathrm{E}$ be the value, at a given moment, of the electromotive force resulting from the primitive magnetic field-that is to say, of the field as it exists when the induced system is at rest; and let $I$ be the quantity of electricity set in motion during the time $d t$, starting from that moment. The electromagnetic work is equal to EIdt, and is found again in the thermal work of the current $I^{2} R d t$ and in the work of the inverse electromotive forces which spring from the reactions of the various parts of the machine. Experience shows that the reactions upon the inducing electromagnets are negligible; for the current of the excitatrix, measured by an extremely sensitive galvanometer, shows no variation when the induced circuit is closed or when it is opened; therefore the reactions are reduced to the induction of the current upon itself. If we represent by $U$ the flow of force emanating from the induced system when it is traversed by the unit of current, and, consequently, by $\frac{U}{2}$ what is called the

* Comptes Rendus, July 26, 1880. 
coefficient of self-induction, the work of the extra current during the time $d t$ has the value $\mathrm{UI} \frac{d \mathrm{I}}{d t} d t$. We have, then, the equation

or, dividing by $\mathrm{I}$ and by $d t$,

$$
\mathrm{EI} d t=\mathrm{I}^{2} d t+\mathrm{UI} \mathrm{I}_{\overline{d t}}^{d \mathrm{I}} d t
$$

$$
\mathbf{E}=\mathrm{IR}+\mathrm{U}_{\overline{d t}}^{d \mathrm{I}} \cdot \text {. . . . . . . . . . }
$$

This equation is no other than that given by Helmholtz, from which he deduced the laws of the induced currents which are produced at the moment of the closing and of the opening of the circuit of the pile-with this difference, however, that in M. Helmholtz's formula the quantity $\mathrm{E}$ is a constant, while here it is a function of the time.

To determine this function I operated as follows :-I put the induced system into communication with a Thomson galvanometer with the oscillations not deadened; and, the arc corresponding to the half-period of the machine having been divided into ten equal parts, by means of a very simple arrangement I caused the induced system to run over abruptly in succession the ten consecutive intervals. The arc of impulsion of the galvanometer measures each time the total quantity of electricity set in motion, and consequently the electromotive force corresponding to the successive displacements. The electromotive force thus measured is certainly that resulting from the primitive field, since in each displacement the quantities of electricity due to the reactions have a sum identically nil. The curve thus obtained does not sensibly differ from a sinusoid; we can therefore assume that $\mathrm{E}$ is of the form $\mathrm{E}_{0} \sin m t$, the time being counted from the moment when the axis of the induced coincides with that of the inducing coil. Under these conditions, and putting

$$
\tan 2 \pi \phi+\frac{2 \pi}{\mathrm{T}} \frac{\mathrm{U}}{\mathrm{R}}, \cdot \text {. . . . . . . . }
$$

the integral of equation (1) can be written

$$
i=\frac{\mathrm{E}_{0}}{\left(\mathrm{R}^{2}+\frac{4 \pi^{2}}{\mathrm{~T}}\right)^{2}} \sin 2 \pi\left(\frac{t}{\mathrm{~T}}-\phi\right)=\mathrm{A} \sin 2 \pi\left(\frac{t}{\mathrm{~T}}-\phi\right),
$$

the constant being determined by the condition that $t=\phi \mathrm{T}$ when the intensity is nil. The intensity of the current at each instant is therefore represented by a sinusoid, of which $A$ is the amplitade and $\phi$ the phase.

The total quantity of electricity which passes in the circuit during half a period has for its value

$$
\phi=\int_{t=T \phi}^{t=\phi T+\frac{T}{2}} i d t=A \int_{t=\phi T}^{t=\Phi T+\frac{T}{2}} \sin (n t-2 \pi \phi) d t \frac{A T}{\pi} ; .
$$


and we find, for the mean intensity $I$,

$$
\mathrm{I}=\frac{2 \mathrm{~A}}{\pi}=\frac{\frac{2 \mathrm{E}}{\pi}}{\left(\mathrm{R}^{2}+\frac{4 \pi^{2} \mathrm{U}^{2}}{\mathrm{~T}^{2}}\right)^{\frac{1}{2}}} . \quad \cdot \ldots .
$$

The electrometer, in the conditions in which I use it, does not give this mean intensity, but the square root of the mean of the squares of the intensities-that is to say, an intensity I' satisfying the condition

From this we deduce

$$
I^{\prime 2} \frac{T}{2}=A^{2} \int_{t=\phi T}^{t=\phi T+\frac{T}{2}} \sin ^{2}(m t-2 \pi \phi) d t=\frac{A^{2} T}{4} .
$$

and consequently

$$
I^{\prime}=\frac{A}{\sqrt{ } 2},
$$

$$
\frac{\mathrm{I}^{\prime}}{\mathrm{I}}=\frac{\pi}{2 \sqrt{ } 2}=1: 11 \text {. }
$$

The formula to be compared with the experiments is therefore

$$
I^{\prime}=\frac{\frac{E_{0}}{\sqrt{2}}}{\left(R^{2}+\frac{4 \pi^{2} U^{2}}{T^{2}}\right)^{\frac{1}{2}}},
$$

-that is to say, the formula to which I had been empirically conducted.-Comptes Rendus de l'Académie des Sciences, Sept. 6, 1880, t. xci. pp. $468-470$.

ON AN ACOUSTIC METHOD OF DETERMINING VAPOUR-DENSITIES. BY H. GOLDSCHMIDT*

From Laplace's formula for the velocity of sound in gases there results for the ratio of the densities of two gases $d$ and $\mathrm{D}$ which, successively set in vibration in the same tube, give tones of the vibration-periods $n$ and $\mathrm{N}$,

For $\mathrm{D}=1$ (air),

$$
d: \mathrm{D}=\mathrm{N}^{2}: n^{2} .
$$

$$
d=\mathrm{N}^{2}: n^{2}=\text { air-tone } \mathrm{e}^{2}: \text { gas-tone } \mathrm{e}^{2} .
$$

The author raps the test-tube filled with the gas in question, and seeks the resulting tone upon a violin. This procedure is applicable also to substances which are liquid at ordinary temperature. The test-tube, containing a small quantity of the substance, is closed above with a caoutchouc stopper through which passes a capillary tube, and brought to evaporation in steam. When no more vapour issues from the capillary tube, the stopper is pulled out and the tone then heard is determined. The observed agree very well with the calculated values.-Wiedemann's Beiblätter, 1880, No.7, p. 500.

* Chem. Ber. xiii. pp. 768-771 (1880). 